\title{
Beetroot juice - a suitable post-marathon metabolic recovery supplement?
}

Zinandré Stander $^{1,2^{*}} \mathbb{D}$, Laneke Luies ${ }^{1} \mathbb{D}$, Mari van Reenen ${ }^{1} \mathbb{D}$, Glyn Howatson ${ }^{3,4} \mathbb{D}$, Karen M. Keane ${ }^{5}$, Tom Clifford ${ }^{6,7}$ (D) Emma J. Stevenson ${ }^{5}$ (iD and Du Toit Loots ${ }^{1}$ (D)

\begin{abstract}
Background: Red beetroot (Beta vulgaris L.) is a multifunctional functional food that reportedly exhibits potent antiinflammatory, antioxidant, vasodilation, and cellular regulatory properties. This vegetable has gained a fair amount of scientific attention as a possible cost-effective supplement to enhance performance and expedite recovery after physical exercise. To date, no study has investigated the effects of incremental beetroot juice ingestion on the metabolic recovery of athletes after an endurance race. Considering this, as well as the beneficial glucose and insulin regulatory roles of beetroot, this study investigated the effects of beetroot juice supplementation on the metabolic recovery trend of athletes within $48 \mathrm{~h}$ after completing a marathon.

Methods: By employing an untargeted two-dimensional gas chromatography time-of-flight mass spectrometry approach, serum samples (collected pre-, post-, $24 \mathrm{~h}$ post-, and $48 \mathrm{~h}$ post-marathon) of 31 marathon athletes that ingested a series $(n=7 ; 250 \mathrm{ml}$ ) of either beetroot juice ( $n=15$ athletes) or isocaloric placebo ( $n=16$ athletes) supplements within $48 \mathrm{~h}$ post-marathon, were analysed and statistically compared.
\end{abstract}

Results: The metabolic profiles of the beetroot-ingesting cohort recovered to a pre-marathon-related state within $48 \mathrm{~h}$ post-marathon, mimicking the metabolic recovery trend observed in the placebo cohort. Since random interindividual variation was observed immediately post-marathon, only metabolites with large practical significance ( $p$ value $\leq 0.05$ and $d$-value $\geq 0.5$ ) within $24 \mathrm{~h}$ and $48 \mathrm{~h}$ post-marathon were considered representative of the effects of beetroot juice on metabolic recovery. These $(n=4)$ mainly included carbohydrates (arabitol and xylose) and oddchain fatty acids (nonanoate and undecanoate). The majority of these were attributed to beetroot content and possible microbial fermentation thereof.

Conclusion: Apart from the global metabolic recovery trends of the two opposing cohorts, it appears that beetroot ingestion did not expedite metabolic recovery in athletes within $48 \mathrm{~h}$ post-marathon.

Keywords: Beta vulgaris L., Beetroot juice, Endurance running, Recovery, Metabolism, Functional foods

\footnotetext{
* Correspondence: 25098365@nwu.ac.za

'Human Metabolomics, North-West University, Potchefstroom 2531, South

Africa

${ }^{2}$ North-West University, Potchefstroom Campus, Private Bag X6001, Box 269,

Potchefstroom 2520, South Africa

Full list of author information is available at the end of the article
}

(c) The Author(s). 2021 Open Access This article is licensed under a Creative Commons Attribution 4.0 International License, which permits use, sharing, adaptation, distribution and reproduction in any medium or format, as long as you give appropriate credit to the original author(s) and the source, provide a link to the Creative Commons licence, and indicate if changes were made. The images or other third party material in this article are included in the article's Creative Commons licence, unless indicated otherwise in a credit line to the material. If material is not included in the article's Creative Commons licence and your intended use is not permitted by statutory regulation or exceeds the permitted use, you will need to obtain permission directly from the copyright holder. To view a copy of this licence, visit http://creativecommons.org/licenses/by/4.0/ The Creative Commons Public Domain Dedication waiver (http://creativecommons.org/publicdomain/zero/1.0/) applies to the data made available in this article, unless otherwise stated in a credit line to the data. 


\section{Background}

In addition to the well-established physiological [1] and immunological [2] health effects of endurance running races $(>5 \mathrm{~km})$, this sport induces a wide variety of metabolic adaptations [3] (The acute systematic biochemical adaptations induced by endurance running, submitted). These adaptations are primarily associated with fuel substrate catabolism and typically include elevated glycolysis, lipolysis, amino acid oxidation, ketogenesis, and tricarboxylate cycle (TCA) intermediates [4-8]. Additionally, previously reported elevations in dicarboxylic acids, $\alpha$-hydroxy acids and odd chain fatty acids coupled with reduced phospholipids, suggest the activation of alternative energy-producing pathways such as $\omega$ and/or $\alpha$-oxidation of fatty acids, as well as autophagy of cellular membranes $[4,9]$. These adaptations, along with fluctuations in purine and pyrimidine, urea cycle, and reactive oxygen intermediates $[4,5,7,8,10]$ not only further attest to the extensive energy-taxing nature of endurance running, but also emphasize the metabolic flexibility of athletes to use multiple fuel substrates during endurance races, to supply the necessary energy to complete the event. Based on previous literature, these metabolic adaptations recover to preexercise-related levels within $3-72 \mathrm{~h}$ after cessation of endurance exercise [11-14], depending on the intensity, duration, and distance of the running event. Post-exercise metabolic restoration is mainly attributed to a reduction in energy requirements, which leads to the inactivation of catabolic pathways required for energy production, and the activation of anabolic pathways required for recovery, including the nucleotide salvage pathways, glycogenesis, lipogenesis and protein synthesis $[11,12,14]$.

Besides the potentially detrimental effects induced by marathons and/or ultramarathons, these are still considered a popular leisure activity, globally. As such, a growing body of research is aimed at identifying more costeffective strategies that may expedite the recovery process, and subsequently enhancing athlete performance. One of these strategies includes pre- and/or post-exercise ingestion of supplements that either consists of or contains functional foods. Functional foods are primarily defined as any natural and/or fortified foods, rich in bioactive compounds that possess an added advantage to human health besides its nutritional value $[15,16]$. Besides the various beneficial health attributes [17-19], phytonutrient-rich fruits and vegetables are also well-known for their radical scavenging, antioxidant, anti-inflammatory and anti-viral/ microbial properties $[18,20]$ that may aid in performanceenhancing and/or physiological recovery of athletes during and/or after exercise. To date, some of the foods that have been investigated for this particular purpose include cherries, blueberries, carrots, bananas, beetroot, blackcurrants, pomegranates, pears, etc. [21-27]. Moreover, it has been proposed that the anti-oxidant and anti-inflammatory capacity of beetroot (Beta vulgaris L.) surpasses that of most other fruits and vegetables due to its abundant betalain, among other phytochemicals (polyphenols, vitamin C, rutin, epicatechin, etc.) content, which inhibits cyclooxygenase activity and disrupts nuclear factor kappa-lightchain-enhancer of activated B cells (NF-kB) [19]. In addition to these pigment imposing betalains, beetroot is also considered a Class A performance-enhancing supplement (supported by adequate scientific research) by the Australian Institute of Sport [28] due to its nitrate donating abilities. Nitrate reportedly enhances nitric oxide bioavailability via the nitrate-nitrite-nitric-oxide pathway, subsequently enhancing vasodilation, cellular respiration regulation and neurotransmission $[21,29,30]$. Besides the successful application of beetroot juice as a performanceenhancing supplement, controversial evidence exists regarding its ability to expedite the physiological recovery process after exercise [21, 31]. To our knowledge, no study has investigated the capacity of beetroot juice to facilitate metabolic recovery after endurance running.

Thus, in this double-blinded, placebo-controlled investigation, an untargeted two-dimensional gas chromatography time-of-flight mass spectrometry approach (GCxGC-TOFMS) metabolomics approach was used to determine whether or not beetroot juice ingestion possesses an added advantage towards metabolic recovery when compared to unaided recovery within $48 \mathrm{~h}$ postmarathon. This knowledge could not only further improve the current understanding of beetroot aided recovery, but also provide clues to new, more effective beetroot supplementation strategies after exercise.

\section{Methods and materials}

Considering that this project forms part of a larger study that consists of multiple (inter-disciplinary) aims, participant recruitment and selection information [21], additional clinical and physiological measurements [21], as well as complementary metabolic investigations $[4,14]$ based on sub-divisions of the current cohort, have already been published and may be referred to for additional information not pertinent to this investigation.

\section{Participants}

The participants included in this investigation were selected at random and participation was completely voluntary. Prior to the marathon, all participants were required to complete a health and dietary questionnaire (with an additional menstrual cycle questionnaire for female participants), of which individuals receiving or using any anti-inflammatory treatments, chronic medication, as well as those with any food allergies, cardiovascular complications or musculoskeletal disorders and injuries were excluded from the study. All athletes were 
instructed to refrain from exercising and/or using any alternative recovery modalities (heat, cryotherapy, inflammatory drugs, antioxidant vitamins, compression garments, etc.) during the recovery period of this investigation. Withal, the use of anti-bacterial mouth wash was prohibited as a means of conserving the proposed bacterial nitrate-nitrite conversion of beetroot juice in the oral cavity. All the participants gave written and informed consent before the commencement of any analysis. An overview of the participant characteristics/ demographics is presented in Table 1.

\section{Clinical samples and supplementation}

Blood samples of 31 athletes (19 males; 12 females) were obtained (antecubital venesection) before (P0), after (P1), as well as $24 \mathrm{~h}$ (P2) and $48 \mathrm{~h}$ (P3) after completing the Druridge Bay Marathon (Northumberland, UK) [21]. During the two consecutive days following the race, athletes received either beetroot juice $(n=15$ athletes; 9 males and 6 females) or isocaloric placebo supplements ( $n=16$ athletes; 10 males and 6 females). Placebo samples consisted of a maltodextrin, protein powder, and fruit squash mixture, with a similar macro-nutrient content to that of the beetroot juice supplement (containing approximately $400 \mathrm{mg}$ of phenolic compounds and 194 $\mathrm{mg}$ of the pigment, betanin), as described by Clifford, Allerton [21] and indicated in Table S2. These supplements were placed in containers that were indistinguishable in appearance and were consumed as follows: $3 \times$ $250 \mathrm{ml}$ supplements on the day of the marathon (immediately after P1 sampling, $\pm 3 \mathrm{~h}$ post-race, and at 20:00), $3 \times 250 \mathrm{ml}$ supplements on the first day after the marathon (upon waking-up, with lunch, and with supper), and $1 \times 250 \mathrm{ml}$ supplement upon waking on the second day post-marathon. Participant groups were matched according to predicted marathon finishing times and did not significantly differ in terms of recorded dietary intake (determined using Nutritics dietary analysis software), or the number of males/females per group [21]. P0 samples were collected at participant-convenient times preceding the race and patients were required to be in a hydrated yet fasted (for at least $4 \mathrm{~h}$ ) state, whereas P1 samples were acquired within $30 \mathrm{~min}$ after completing the race, thus dictating the approximate time of P2 and P3 collection. All the blood samples were collected in $10 \mathrm{~mL}$ vacutainer vials and placed on ice before being transported to the Northumbria University (Newcastle upon Tyne, UK), Faculty of Health and Life Sciences (Department of Sport, Exercise and Rehabilitation) laboratory, for further processing. Initial sample processing included clotting at room temperature for $30 \mathrm{~min}$, followed by a $10 \mathrm{~min}$ centrifugation step $(3000 \mathrm{~g})$. The serum (supernatant) was then extracted, immediately frozen $\left(-80^{\circ} \mathrm{C}\right)$, and transported on dry ice to the North-West University, Human Metabolomics: Laboratory of Infectious and Acquired Diseases for metabolomics analyses. All samples were stored at $-80^{\circ} \mathrm{C}$ until analysis commenced. A schematic representation of the larger metabolic study design is presented in Fig. S1 of this investigation and the Supplementary material of Stander, Luies [14].

\section{Total metabolome extraction and derivatisation}

As previously described [4, 14], all samples, including pooled quality control samples (containing $50 \mu \mathrm{l}$ of each sample), were subjected to an in-house total metabolome extraction (SOP number: HM-MET-056) and traditional TMCS derivatisation before being analysed. To summarise; $50 \mu \mathrm{l}$ of internal standard (3-phenylbutyrate; $0.45 \mu \mathrm{g}$ / $\mathrm{ml})$, dissolved in a chloroform:methanol:milliQ water (1:3: 1) solution, was added to smaller aliquots $(50 \mu \mathrm{l})$ of the samples. While on ice, $300 \mu \mathrm{l}$ of ice-cold acetonitrile was added to the aliquots, whereupon it was mixed for $2 \mathrm{~min}$ (REAX D-91126 vortex; Heidolph Instruments GmbH \& Co.KG, Schwabach, Germany), and centrifuged for $10 \mathrm{~min}$ at $4000 \mathrm{rpm}$. The supernatants of the samples were then extracted, transferred to glass GC-MS vials, placed in a heating block set to $40{ }^{\circ} \mathrm{C}$, and dried under a stream of nitrogen gas for approximately $45 \mathrm{~min}$. Using a Hamilton syringe, $25 \mu \mathrm{l}$ of methoxamine hydrochloride (dissolved in $15 \mathrm{mg} / \mathrm{ml}$ pyridine) was added to each vial, which proceeded to incubate for $90 \mathrm{~min}$ at $50^{\circ} \mathrm{C}$. Finally, samples were derivatised with $40 \mu \mathrm{l}$ BSTFA (enriched with $1 \%$ TMCS) for $60 \mathrm{~min}$ at $60^{\circ} \mathrm{C}$, before being transferred to a new $\mathrm{GC}$ vial containing a vial insert.

Table 1 A summary of the participant characteristics of the placebo and beetroot ingesting cohorts

\begin{tabular}{lll}
\hline $\begin{array}{l}\text { Participant demographical } \\
\text { information }\end{array}$ & $\begin{array}{l}\text { Placebo cohort }(\boldsymbol{n}=\mathbf{1 6}) \\
\text { Average } \pm \text { standard deviation }\end{array}$ & Beetroot cohort $(\boldsymbol{n}=\mathbf{1 5})$ \\
\hline Age (years) & $39 \pm 12$ & $42 \pm 10$ \\
Pre-marathon athlete weight $(\mathrm{kg})$ & $72.2 \pm 11.9$ & $70.3 \pm 7.9$ \\
Post-marathon athlete weight $(\mathrm{kg})$ & $70.8 \pm 11.7$ & $69 \pm 7.4$ \\
Marathon experience (years) & $8 \pm 7$ & $11 \pm 10$ \\
Finishing time (hh:mm:ss) & $04: 30: 25 \pm 00: 36: 48$ & $04: 07: 08 \pm 00: 39: 16$ \\
\hline
\end{tabular}




\section{GCxGC-TOFMS analysis and processing}

The randomised samples were injected $(1 \mu \mathrm{l} ; 1: 3$ split ratio) into the Pegasus 4D GCxGC-TOFMS system (LECO Africa (Pty) Ltd., Johannesburg, South Africa), using the Gerstel auto-sampler (Gerstel $\mathrm{GmbH}$ and co. KG, Mülheim van der Ruhr, Germany). The carrier gas (purified helium) was set to flow at a constant rate of $1 \mathrm{ml} /$ min, while the injector temperature was held at $270{ }^{\circ} \mathrm{C}$. The primary oven, containing a Restek Rxi-5MS capillary column $(30 \mathrm{~m} ; 0.25 \mu \mathrm{m}$ diameter and $0.25 \mu \mathrm{m}$ film thickness), was programmed with an initial temperature of $70^{\circ} \mathrm{C}$, which incrementally $\left(4{ }^{\circ} \mathrm{C} / \mathrm{min}\right)$ increased until a final temperature of $300^{\circ} \mathrm{C}$ was reached (maintained for $2 \mathrm{~min}$ ). The secondary oven, containing a Restek Rxi17 capillary column $(1 \mathrm{~m} ; 0.25 \mu \mathrm{m}$ diameter and $0.25 \mu \mathrm{m}$ film thickness), was set at $85^{\circ} \mathrm{C}$, which increased with $4.5^{\circ} \mathrm{C} / \mathrm{min}$ until a final temperature of $300^{\circ} \mathrm{C}$ was reached (maintained for $2 \mathrm{~min}$ ), while the thermal modulator pulsed cold and hot streams nitrogen gas every $3 \mathrm{~s}$ for a duration of $0.5 \mathrm{~s}$. The mass spectra (ms) of the first $400 \mathrm{~s}$ of each run was discarded (regarded as solvent delay), whereafter $\mathrm{ms}$ of ions $(50-800 \mathrm{~m} / \mathrm{z}$ ) were acquired at $200 \mathrm{~ms} / \mathrm{s}$. The transfer line and ion source were held at $270^{\circ} \mathrm{C}$ and $220^{\circ} \mathrm{C}$, respectively, with a detector voltage of $1600 \mathrm{~V}$ and filament bias of $-70 \mathrm{eV}$. The data generated from the GCxGC-TOFMS was processed (deconvolution, peak alignment and identification) using the ChromaTOF Software (LECO Corporation), as described by Stander, Luies [4].

\section{Data processing and statistical analyses}

The dataset obtained was normalised relative to the internal standard, and plasticizers, analytical contaminants, and column-related compounds were removed. Hereafter, a $50 \%$ zero value filter, zero value replacement (with random values below the detection limit), 50\% quality control coefficient of variation (QC-CV) filter (retaining metabolites with a $\mathrm{CV} \leq 50 \%$ ), log transformation, and auto-scaling were performed.

Following these clean-up steps, the data was subjected to a variety of multivariate and univariate statistical methods using MATLAB [32] (in conjunction with a PLS [33] toolbox), as a means of selecting those metabolites pertinent to the aim of this investigation. To comprehensively address the aim of this investigation, multiple statistical objectives, and therefore comparisons, were required. In summary, paired statistical analysis of the beetroot juice-ingesting cohort was performed to confirm whether this cohort indeed recovered to a pre-marathon-related state within $48 \mathrm{~h}$ (statistical objective A), as has already been confirmed for the placebo group [14]. Hence, the P2 and P3 serum metabolite profiles of the beetroot-ingesting cohort were respectively compared to that of the P0 profile to identify any differentiating metabolites which would oppose metabolic recovery. Multivariate analyses included multilevel (ML) principal component analyses (PCA) and MLpartial squares discriminant analysis (ML-PLS-DA), while univariate analyses consisted of a paired t-test, and effect size tests, to assess statistical and practical significance respectively. To control for false discovery rates (FDR) associated with large scale multiple testing, as in the case of untargeted metabolomics datasets, t-test $p$-values were adjusted using the Benjamini-Hochberg procedure (limiting FDRs to 5\%). All metabolites (P0 vs $\mathrm{P} 2$ and $\mathrm{P} 0$ vs $\mathrm{P} 3$ ) with a $\mathrm{BH}$ adjusted $p$-value $\leq 0.05$ and an effect size $d$-value $\geq 0.5$ were deemed significant.

To determine whether or not beetroot juice ingestion expedites the metabolic recovery trend of athletes within $48 \mathrm{~h}$ post-marathon, unpaired statistical analyses of the beetroot cohort vs placebo cohort were performed (statistical objective B). Foremost, the metabolic progression for both treatment groups over time was compared by using statistical models that accounted for the entire experimental design and dependencies between measures, i.e. a two-way repeated-measures analysis of variance (RM ANOVA), and an unfolded PCA. The latter transforms a three-dimensional tensor into a twodimensional matrix (Fig. S2), thus allowing for PCA [34]. To supplement these comprehensive statistical methods, recovery time-point-specific inter-cohort comparisons were performed to assess day-specific variation that may be apparent between the cohorts. For this, multivariate statistical methods included PCA, PLS-DA, whilst univariate methods comprised an independent samples $\mathrm{t}$ test (FDR's controlled to 5\% according to the $\mathrm{BH}$ procedure), and independent effect size tests based on Cohen's $d$-values. Here, variables were selected based on a BH adjusted $p$-value $\leq 0.05$ or a Cohen's $d$-value $\geq 1.0$, thus considering both statistical and practical significance. As opposed to the equal statistical and practical relevance of marker selection in objective A, this objective's selection was more stringent on practical relevance to capture slight differences that may be of practical importance.

Since the cohort sizes of this investigation are relatively small, multivariate models are less readily validated and could therefore only be used to visualise trends and variation, whilst univariate models, better equipped to avoid false discoveries, were employed for variable selection in both statistical objectives.

\section{Results}

When comparing both the P2 and P3 serum metabolite profiles of the beetroot cohort to the corresponding P0 profiles (statistical objective A), no metabolite markers were considered statistically significant $(\mathrm{BH} p$-value 
$\leq 0.05$ and $d$-value $\geq 0.5$ ), suggesting that the metabolome of the beetroot cohort recovered to a baseline-related state within $24 \mathrm{~h}$ post-marathon. This was further indicated by the confined positioning of the respective ML-PCA of each recovery time-point relative to the P0 ellipsoids, as presented in Fig. 1.

Since these results correspond with the findings of Stander, Luies [14] that indicated overall metabolic restoration of the placebo athletes within $48 \mathrm{~h}$ postmarathon, an unfolded PCA was constructed to visualise the time-dependent global metabolic recovery trend of the two cohorts relative to each other (Fig. 2) (statistical objective B).

Based on the unfolded PCA plots it is evident that the most significant effect emanated from the marathon perturbation [4], after which both groups returned to a pre-marathon-related state within $\pm 24 \mathrm{~h}$ [14]. Intensely overlapped confidence intervals of the recovery timepoints of the beetroot juice and placebo cohorts suggest little to no variation between groups at these times (Fig. 2a). However, upon removal of confidence intervals, P2 and P3 centroids of the beetroot cohort are seemingly slightly closer to that of P0 (Fig. 2b), which could be indicative of small inter-cohort differences. As such, a twoway RM ANOVA was employed, and 16 metabolites were identified as having a statistically significant ( $p$-value $\leq 0.05$ ) interaction (between time and intervention) and/or intervention effect (Table 2). Considering that this univariate method focuses on relatively small differences within the entire study design (P0-P3), the RM ANOVA alone does not discriminate the precise origin of the metabolic fluctuation observed. Consequently, pairwise comparisons of the different time-points were employed to determine day-specific recovery effects. Whilst the PCA plots of each time-point comparison (Fig. S3) did not visually portray significant differences between the groups at the different time-points, Cohen's $d$-values for the majority of these RM ANOVA metabolites indicated random, moderate-to- large practical variance amongst the groups (Table 2). A more detailed table including RM ANOVA $p$-values as well as average metabolite concentrations and standard deviations can be found in Table S1.

In light of the pre-existing individual variance (particularly at P1), as well as the lack in statistical significance of metabolites ( $\mathrm{BH} p$-value $\leq 0.05$ ) during the recovery period (P2 and P3), only those metabolites with a large effect $(d$-value $\geq 1.0)$ at the respective recovery timepoints were considered relevant in terms of understanding any possible treatment-induced differences at various stages of recovery (P2 and P3), when comparing the beetroot and the placebo cohort. Based on this, only four metabolites (arabitol, nonanoate, undecanoate and xylose) were identified as significantly altered when comparing these cohorts (indicated with an asterisk in Table 2 ), while significant $p$ - and $d$-values are emphasized in bold.

\section{Discussion}

Beetroot juice has gained a considerable amount of attention as a possible performance optimisation and recovery enhancing sports supplement due to its potent reactive oxygen scavenging properties and its ability to promote vasodilation, regulate cellular respiration and reduce inflammation $[19,35]$. However, limited literature is available pertaining to the metabolic recovery effects of beetroot juice after endurance running exercises. In order to completely ascertain whether or not beetroot juice possess an added advantage in terms of metabolic recovery within $48 \mathrm{~h}$ post-marathon, it is imperative to also comprehend the unaided metabolic recovery of athletes within the same timeframe. These results have been published as part of a previous investigation [14], and will therefore only be summarised here. Unaided metabolic recovery was attained within $24 \mathrm{~h}$ post-marathon (with exception of xylose), and included reductions in carbohydrates, fatty acids, and TCA cycle intermediates,
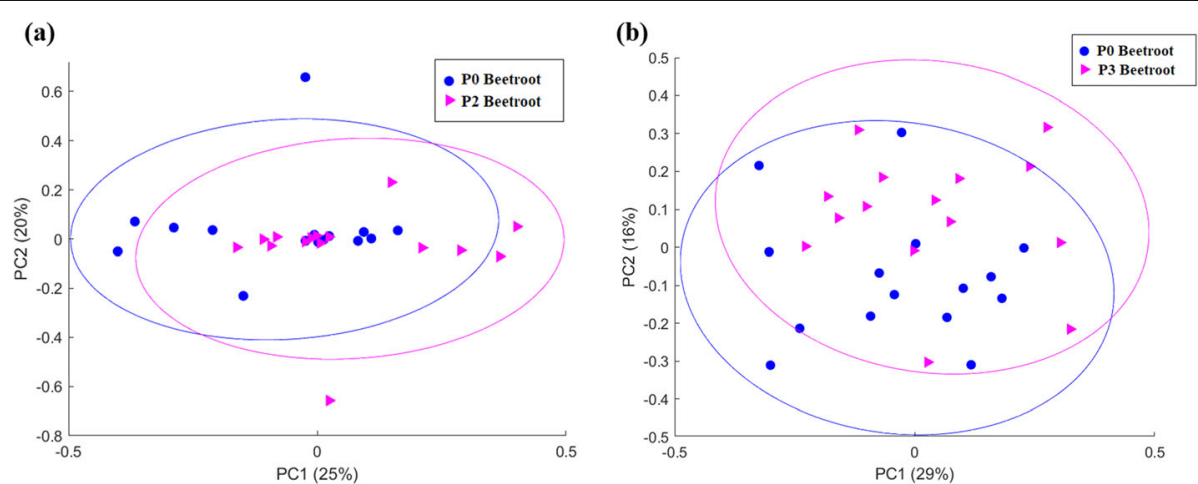

Fig. 1 Multi-level principal component analysis plot of the pre-marathon [P0] serum metabolite profiles of the beetroot group relative to the (a) $24 \mathrm{~h}$ post-marathon [P1] and (b) $48 \mathrm{~h}$ post-marathon metabolite profiles [P2], profiles of the same group. Abbreviations: PC: principal component. The ellipsoids represent $90 \%$ confidence intervals of each centroid 
(a)

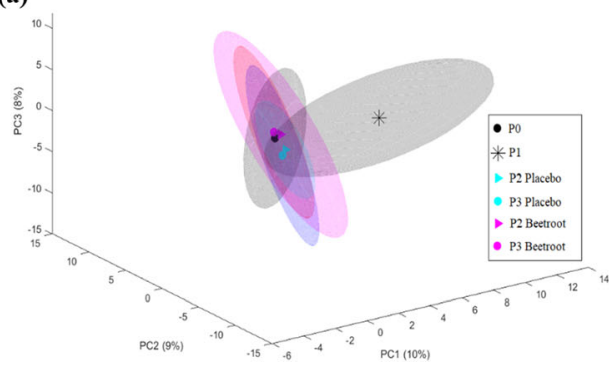

(b)

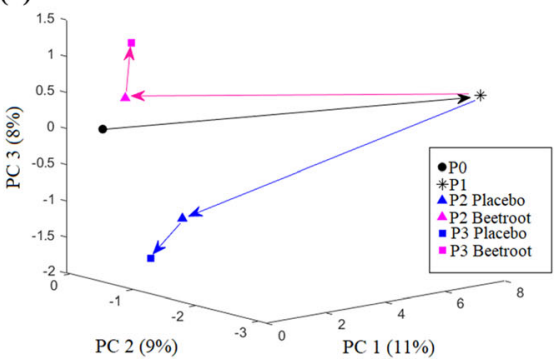

Fig. 2 Unfolded principal component analysis (a) with, and (b) without confidence intervals, depicting the global recovery trend of the beetroot and placebo cohort over time. Abbreviations: P0: pre-marathon; P1: post-marathon; P2: $24 \mathrm{~h}$ post-marathon; P3: $48 \mathrm{~h}$ post-marathon; PC: principal component. The ellipsoids in (a) represent $90 \%$ confidence intervals of each centroid

along with elevations in amino acids. Recovery of these was ascribed to a reduction in energy requirements, leading to the activation of glucogenesis, fatty acid reesterification, protein synthesis, cellular membrane restoration and the possible activation of nucleotide salvage pathways $[14,36]$. In this investigation, a comprehensive comparison of the recovery trends of the beetroot juice and placebo cohorts did not vary significantly (Fig. 2), thus indicating no added advantage of beetroot juice ingestion in terms of metabolic recovery after the marathon. However, when employing a two-way RM ANOVA, significant (albeit small) concentration fluctuations were observed in 16 metabolites (Table 2). Whilst these fluctuations were significant when considering the entire study design, pairwise analysis of the respective time-points later revealed that a large portion is owed to P1 (and to some extent P0) variation between athletes. Besides the inevitable confounder of genetic, age and gender variation, these P1 disparities are to be expected since the dietary regimens of athletes were not restricted and/or controlled at either of these time-points as a means of providing a more relatable, robust representation of the marathon perturbation [4]. Regardless, while the substantial impact of the marathon perturbation overshadowed these differences [4], the effect of beetroot juice supplementation is evidently negligible [21, 37].

Table 2 Metabolites varying significantly between the beetroot and placebo cohorts, according to RM ANOVA and day-specific pairwise comparisons

\begin{tabular}{|c|c|c|c|c|c|c|c|c|}
\hline \multirow[t]{2}{*}{$\begin{array}{l}\text { Metabolite } \\
\text { (PubChem ID) }\end{array}$} & \multicolumn{2}{|c|}{$\begin{array}{l}\text { P0 Placebo vs P0 } \\
\text { Beetroot juice }\end{array}$} & \multicolumn{2}{|c|}{$\begin{array}{l}\text { P1 Placebo vs P1 } \\
\text { Beetroot juice }\end{array}$} & \multicolumn{2}{|c|}{$\begin{array}{l}\text { P2 Placebo vs P2 } \\
\text { Beetroot juice }\end{array}$} & \multicolumn{2}{|c|}{$\begin{array}{l}\text { P3 Placebo vs P3 } \\
\text { Beetroot juice }\end{array}$} \\
\hline & $\begin{array}{l}\mathrm{BH} \\
p \text {-value }\end{array}$ & $\begin{array}{l}\text { Cohen's } \\
d \text {-value }\end{array}$ & $\begin{array}{l}\mathrm{BH} \\
p \text {-value }\end{array}$ & $\begin{array}{l}\text { Cohen's } \\
d \text {-value }\end{array}$ & $\begin{array}{l}\text { BH } \\
p \text {-value }\end{array}$ & $\begin{array}{l}\text { Cohen's } \\
d \text {-value }\end{array}$ & $\begin{array}{l}\mathrm{BH} \\
p \text {-value }\end{array}$ & $\begin{array}{l}\text { Cohen's } \\
d \text {-value }\end{array}$ \\
\hline $\begin{array}{c}\text { a-Oleoylglycerol }(5319879)^{b} \\
\end{array}$ & 0.89 & 0.65 & 0.92 & 0.31 & 1.00 & 0.13 & 0.89 & 0.19 \\
\hline$\beta$-Hydroxydecenedioate $(121232666)^{b}$ & 0.92 & 0.33 & 0.97 & 0.05 & 1.00 & 0.37 & 0.56 & 0.44 \\
\hline$\beta$-Hydroxyphenylacetate $(12122)^{a}$ & 0.97 & 0.22 & 0.92 & 0.60 & 1.00 & 0.34 & 0.27 & 0.85 \\
\hline$\beta$-Hydroxyvalerate (107802) ${ }^{a}$ & 0.92 & 0.33 & 0.92 & 0.54 & 1.00 & 0.58 & 0.31 & 0.64 \\
\hline$p$-Hydroxyphenylacetate $(127)^{a}$ & 0.89 & 0.61 & 0.92 & 0.31 & 1.00 & 0.65 & 0.30 & 0.70 \\
\hline Arabitol $(43925)^{a, b, *}$ & 0.89 & 0.45 & 0.96 & 0.12 & 0.03 & 1.40 & $2.1 \times 10^{-3}$ & 1.73 \\
\hline Eicosanoate $(10467)^{a}$ & 0.89 & 0.58 & 0.92 & 0.46 & 1.00 & 0.36 & 0.50 & 0.56 \\
\hline Glycerol (753) ${ }^{b}$ & 0.97 & 0.13 & 0.92 & 0.57 & 1.00 & 0.24 & 0.99 & 0.02 \\
\hline Hippurate (464) ${ }^{a}$ & 0.89 & 0.59 & 0.92 & 0.39 & 1.00 & 0.19 & 0.27 & 0.86 \\
\hline Mannitol $(6251)^{a}$ & 0.99 & 0.11 & 0.92 & 0.37 & 1.00 & 0.55 & 0.37 & 0.59 \\
\hline Nonanoate (8158) ${ }^{a, *}$ & 0.89 & 0.71 & 0.92 & 0.84 & 0.57 & 1.02 & $2.6 \times 10^{-3}$ & 1.63 \\
\hline Oxalate (971) ${ }^{a}$ & 0.89 & 0.40 & 0.92 & 0.79 & 1.00 & 0.49 & 0.92 & 0.12 \\
\hline Rhamnose (25310) & 0.89 & 0.63 & 0.92 & 0.46 & 1.00 & 0.65 & 0.88 & 0.22 \\
\hline Threonate (21145021) a,b & 0.88 & 0.61 & 0.89 & 1.03 & 1.00 & 0.30 & 0.52 & 0.58 \\
\hline Undecanoate (8180) ${ }^{a,{ }^{*}}$ & 0.40 & 1.24 & 0.92 & 1.07 & 1.00 & 0.35 & 0.04 & 1.38 \\
\hline Xylose (135191) ${ }^{a, b,{ }^{*}}$ & 0.89 & 0.56 & 0.92 & 0.29 & 0.21 & 1.04 & 0.53 & 0.46 \\
\hline
\end{tabular}

Intervention $\left({ }^{a}\right)$, interaction $\left({ }^{b}\right)$ effects, and day-specific significance $\left({ }^{*}\right)$ are indicated in the first column, while day-specific $p$ - and $d$-value significance are indicated in bold 
This is further supported in the study performed by Clifford, Allerton [21], in which beetroot juice supplementation did not attenuate muscle soreness or inflammation, nor did it improve muscle functionality in the same set of athletes. As such, it is unsurprising that only four metabolite markers were identified to vary significantly at the different stages of recovery (P2 and P3). These metabolites (arabitol, xylose, nonanoate, and undecanoate) will be comprehensively discussed below.

In addition to the initial increase of arabitol in both cohorts during the marathon [4], this metabolite continued to increase in the beetroot-ingesting cohort during the recovery period, while contrarily decreasing in the placebo cohort [14]. Although at first glance this may be associated with low-calorie sweetener ingestion, as previously reported to occur during the marathon [4], Love Beets product labels indicated that no additional sweeteners were added to this $99 \%$ organic beetroot juice supplement (with 1\% lemon juice as a stabiliser). However, considering that red beetroot pectin fibres are rich in various sugars including xylose, rhamnose, mannose and especially, arabinose [38], it can be deduced that although not directly added to the supplement, arabitol may have been produced via the reduction of arabinose in the polyol pathway present in humans and various intestinal yeasts $[39,40]$. Furthermore, it has been reported that intestinal bacteria preferentially ferment arabinose over other sugars such as xylose [41], thus further ascribing the elevated xylose bioavailability at $\mathrm{P} 2$ in this cohort. In addition, xylose can serve as a minor precursor for ribose, the latter which is a key component in the uridine-dependent salvage pathway during recovery [14]. As such, since beetroot phytonutrients, including betaines [42], folate [43], and glutamine [38], can assist in the process of nucleotide restoration, the observed P2 elevations in xylose could also partially be indicative of the role of beetroot-promoting nucleotide synthesis via alternative constituents, subsequently reducing the incorporation of xylose to produce ribose. Although still being significantly elevated compared to the placebo cohort, slight P3 reductions (compared to P2) in both arabitol (significant) and xylose (non-significant) were observed in the beetroot juice cohort and may be attributed to the fact that only a single beetroot supplement (upon waking) was ingested on the final day of the investigation (P3), as opposed to the three servings at P1 and P2. Nevertheless, arabitol has been associated with numerous health benefits, of which the prevention of blood sugar dysregulation and fat deposition in the intestinal tract [40] is the most applicable to post-race metabolic recovery.

Opposing fluctuations in OCFA (nonanoate and undecanoate) concentrations were observed during recovery. In general, reductions in undecenoate $\left(C_{11}\right)$ observed in both cohorts within $24 \mathrm{~h}$ post-marathon, is most likely due to residual catabolism of the accumulated fatty acids via $\alpha$-oxidation [4]. This is further supported by elevations in nonanoate $\left(C_{9}\right)$ in both cohorts during this time since it is a downstream product of undecanoate catabolism. Nevertheless, mitigation of OCFA catabolism is evident by the reduction in both nonanoate and undecanoate concentrations in the placebo cohort within 48 $\mathrm{h}$ post-marathon. Contrarily, however, both of these OCFAs are elevated in the beetroot cohort $48 \mathrm{~h}$ postmarathon, possibly indicating the activation of OCFA synthesis in this cohort. The proposed mechanism of action for this includes the fermentation of beetroot sugar-content to propanoate via intestinal bacteria (Bacteriodetes, Clostridium, Lactobacillus, etc.) [44], which can be further utilised for OCFA synthesis. Argumentatively, placebo supplements evidently contained the same total amount of sugar, however, this did not correlate with an increase in OCFAs $48 \mathrm{~h}$ post-marathon. This may not only be ascribed to the increased propionate-producing bacterial activity (i.e. Lactobacillus) induced by beetroot pectin ingestion [44] but may also arise as a result of the polyphenol content in beetroot which may hinder effective carbohydrate absorption in the intestines [45], subsequently prolonging the exposure of beetroot sugars to gut microbes for fermentation. Besides the possible contribution of OCFA to phospholipid content (i.e. cellular membrane restoration), recent findings have observed an inversed correlation of OCFA and leptin as well as plasminogen-inhibitor-1 [46], further suggesting its role in energy homeostasis regulation and the activation of fibrinolysis. Whether or not elevated OCFAs has an additional advantage pertaining to athlete recovery, remains to be determined.

As with all human-based investigations, an inevitable limitation includes human genotype/phenotype (sex, age, and ethnicity [latter not recorded]) variation confounders, as well as possible dietary variation among athletes. Considering the list of restrictions in terms of recovery modalities and prohibition of anti-bacterial mouth wash provided to the athletes, additional dietary restrictions would have potentially imposed on personalised regimens of these athletes, leading to a reduction in the already confined cohort size. Although not controlled, dietary intake was recorded for the entire duration of this investigation in an attempt to circumvent this. However, these individual variations may introduce a higher level of robustness to the results, providing a more realistic and relatable representation of the metabolic effects of incremental beetroot juice supplementation after a marathon. Since the cohort size of this investigation is considered relatively small in terms of human-based studies and the intricate accompanying statistical approaches needed for analysing the data, future studies consisting of a larger cohort (particularly 
per gender), could further validate these findings and possibly determine the metabolic effects of beetroot juice in a gender-dependent manner. Additionally, the lack of efficacy of beetroot juice observed in this study may be due to the rapid restoration of the metabolism even when not subjected to aiding strategies as well as restricted bioavailability of certain phytonutrients [47, 48] especially at lower dosage administrations [35]. As such, future studies may consider observing the effect(s) of beetroot supplements at shorter incremental time-points along this recovery process (i.e. $6 \mathrm{~h}, 12 \mathrm{~h}, 18 \mathrm{~h}$, etc.) and/ or at higher dosages. Furthermore, since the microbiome of athletes seems to be a key component in the conversion of red beetroot nitrate, the fermentation of sugar components, and metabolism of polyphenols, metabolic studies investigating the effects of beetroot on the gut microbiome and microbial function, could determine the fermentation preferences and possible causes for metabolic delays pertinent to phytonutrient uptake.

\section{Conclusion}

This investigation not only supported previous findings of total metabolic recovery of athletes within $48 \mathrm{~h}$ postmarathon but further indicated that beetroot ingestion does not expedite the metabolic recovery process. Although several significant, albeit small, metabolic fluctuations between cohorts were selected based on univariate statistics, the majority revealed considerable random variation at $\mathrm{P} 1$, which is owed to opposing athletic regimens and inherent biological and physiological aspects. As such, only metabolites with large practical significance at the respective days of the supplement interventions (P2 and P3) were considered when addressing the aim of this investigation. Of the four metabolites identified, the majority were associated with the glycaemic content of red beetroot, as well as the increased microbial activity stimulated by this vegetable. Whether these may provide an additional advantage during an extended period of recovery remains unknown, but as for immediate metabolic recovery, no additional advantage associated with these metabolites were annotated. However, the lack of beetroot juice effectiveness may stem from previously described restricted bioavailability and possible dose-dependent functionality of certain phytonutrients central to the recovery process, and the considerable dependence on the composition and fermentation preferences of gut microbes.

\footnotetext{
Abbreviations

BH: Benjamini-Hochberg; BSTFA: N,O-Bis(trimethylsilyl)trifluoroacetamide; CV: Coefficient of variance; DNA: Deoxyribonucleic acid; FDR: False discovery rates; GC: Gas chromatography; GCxGC-TOFMS: Two-dimensional gas chromatography time-of-flight mass spectrometry; ML: Multilevel; MS: Mass spectrometry; OCFA: Odd-chain fatty acids; P0: Pre-marathon; P1: Postmarathon; P2: $24 \mathrm{~h}$ post-marathon; P3: $48 \mathrm{~h}$ post-marathon; PCA: Principal component analysis; PLS-DA: Partial least squares discriminant analysis;
}

QC: Quality Control; RM ANOVA: Repeated-measures analysis of variance; TCA: Tricarboxylic acid; TMCS: Trimethylchlorosilane

\section{Supplementary Information}

The online version contains supplementary material available at https://doi. org/10.1186/s12970-021-00468-8.

\section{Additional file 1.}

\section{Acknowledgements}

The authors would like to sincerely thank Ms. Derylize Beukes for sample extraction/analysis, and Prof. Nico L. Smit for initiating/managing the institutional collaboration.

\section{Authors' contributions}

The concept and study design were formulated by DTL, ZS, GH, TC, KK, and ES. The samples were acquired from the Northumbria University (GH, TC, KK, and ES) as part of a collaboration agreement with the North-West University. Statistical analyses were performed by MvR, while manuscript drafting, data analysis, and interpretation were performed by ZS. DTL and LL contributed to in-depth data interpretation and the manuscript was repeatedly reviewed by DTL and LL, of which LL provided substantial insights into structural (format) editing. All of the authors reviewed and approved the final draft of this manuscript.

\section{Funding}

This work is based on the research supported in part by the National Research Foundation of South Africa (grant number: 120358). The opinions expressed, and conclusions derived are those of the authors and are not necessarily those of the NRF. The authors have no other specific funding to report. No writing assistance was utilised in the production of this manuscript.

\section{Availability of data and materials}

As the current investigation is part of a larger collaboration study consisting of multiple aims, the dataset of this investigation is not yet publicly available but can be acquired from the corresponding author on reasonable request. The authors declare that all the results included in this study have been presented clearly, honestly and without fabrication, falsification, or inappropriate data manipulation.

\section{Declarations}

\section{Ethics approval and consent to participate}

Ethical approval for this investigation, conducted according to the Declaration of Helsinki and International Conference on Harmonization Guidelines, was obtained from the Research Ethics Committee of the Faculty of Health and Life Sciences at the Northumbria University in Newcastle upon Tyne, UK (reference number: HLSTC120716). Informed, written consent was obtained from all individuals included in the study. No additional consent for publication is required.

\section{Competing interests}

The authors declare that there are no conflicts of interest and that this manuscript has not been submitted/published elsewhere.

\footnotetext{
Author details

'Human Metabolomics, North-West University, Potchefstroom 2531, South Africa. ${ }^{2}$ North-West University, Potchefstroom Campus, Private Bag X6001, Box 269, Potchefstroom 2520, South Africa. ${ }^{3}$ Faculty of Health and Life Sciences, Department of Sport, Exercise and Rehabilitation, Northumbria University, Newcastle upon Tyne NE1 8ST, UK. "Water Research Group, School of Environmental Sciences and Development, North-West University, Potchefstroom 2531, South Africa. ${ }^{5}$ School of Science and computing, Department of Sport Exercise and Nutrition, Galway Mayo Institute of Technology, Galway, Republic of Ireland. ${ }^{6}$ Human Nutrition Research Centre, Faculty of Medicine, Newcastle University, Newcastle upon Tyne, England. ${ }^{7}$ School of Sport, Exercise and Health Sciences, Loughborough University, Loughborough, UK.
} 
Received: 7 May 2021 Accepted: 28 October 2021 Published online: 03 December 2021

\section{References}

1. Knechtle B, Nikolaidis PT. Physiology and pathophysiology in ultra-marathon running. Front Physiol. 2018;9:634. https://doi.org/10.3389/fphys.2018.00634

2. Nieman DC, Pence BD. Exercise immunology: Future directions. J Sport Health Sci. 2019;9(5):432-45. https://doi.org/10.1016/j.jshs.2019.12.003.

3. Daskalaki E, Easton C, Watson DG. The application of metabolomic profiling to the effects of physical activity. Curr Metabolomics. 2014;2(4):233-63. https://doi.org/10.2174/2213235X03666150211000831.

4. Stander Z, Luies L, Mienie LJ, Keane KM, Howatson G, Clifford T, et al. The altered human serum metabolome induced by a marathon. Metabolomics. 2018;14(150):1-11.

5. Schader JF, Haid M, Cecil A, Schoenfeld J, Halle M, Pfeufer A, et al. Metabolite shifts induced by marathon race competition differ between athletes based on level of fitness and performance: A substudy of the EnzyMaglC Study. Metabolites. 2020;10(3)

6. Górecka M, Krzeminski K, Buraczewska M, Kozacz A, Dabrowski J, Ziemba AW. Effect of mountain ultra-marathon running on plasma angiopoietin-like protein 4 and lipid profile in healthy trained men. Eur J Appl Physiol. 2019; 120(1):117-25. https://doi.org/10.1007/s00421-019-04256-w.

7. Li M, Wu Y, Huang G, Chen S, Li S, Cao J, et al. Amino acids changes and muscle damage during the 400 km Ultra Trail Gobi Race. bioRXiv. 2018.

8. Lewis GD, Farrell L, Wood MJ, Martinovic M, Arany Z, Rowe GC, Souza A, Cheng S, McCabe EL, Yang E, Shi X, Deo R, Roth FP, Asnani A, Rhee EP, Systrom DM, Semigran MJ, Vasan RS, Carr SA, Wang TJ, Sabatine MS, Clish CB, Gerszten RE. Metabolic signatures of exercise in human plasma. Sci Transl Med. 2010;2(33):33-7, https://doi.org/10.1126/scitranslmed.3001006.

9. Nieman DC, Sha W, Pappan KL. IL-6 linkage to exercise-induced shifts in lipid-related metabolites: a metabolomics-based analysis. J Proteome Res. 2017;16(2):970-7. https://doi.org/10.1021/acs.jproteome.6b00892.

10. Howe CCF, Alshehri A, Muggeridge D, Mullen AB, Boyd M, Spendiff $O$, et al. Untargeted metabolomics profiling of an $80.5 \mathrm{~km}$ simulated treadmill ultramarathon. Metabolites. 2018:8(14):1-17.

11. Davison G, Vinaixa M, McGovern R, Beltran A, Novials A, Correig X, et al. Metabolomic response to acute hypoxic exercise and recovery in adult males. Front Physiol. 2018;9:1682. https://doi.org/10.3389/fphys.2018.01682.

12. Nieman DC, Shanely RA, Gillitt ND, Pappan KL, Lila MA. Serum metabolic signatures induced by a three-day intensified exercise period persist after 14 h of recovery in runners. J Proteome Res. 2013;12(10):4577-84. https://doi. org/10.1021/pr400717j

13. Daskalaki E, Blackburn G, Kalna G, Zhang T, Anthony N, Watson DG. A study of the effects of exercise on the urinary metabolome using normalisation to individual metabolic output. Metabolites. 2015;5(1):119-39. https://doi.org/1 0.3390/metabo5010119.

14. Stander Z, Luies L, Mienie LJ, Van Reenen M, Howatson G, Keane KM, et al. The unaided recovery of marathon-induced serum metabolome alterations. Sci Rep. 2020;10(1):11060. https://doi.org/10.1038/s41598-020-67884-9.

15. Kareb O, Aider M. Whey and its derivatives for probiotics, prebiotics, synbiotics, and functional foods: a critical review. Probiotics Antimicrob Proteins. 2019;11(2):348-69. https://doi.org/10.1007/s12602-018-9427-6.

16. Tarabella A, Varese E, Buffagni S. Functional Foods. Food Products Evolution: Innovation Drivers and Market Trends. SpringerBriefs in Food, Health, and Nutrition. 2019;117-42

17. Thakur N, Raigond P, Singh Y, Mishra T, Singh B, Lal MK, et al. Recent updates on bioaccessibility of phytonutrients. Trends Food Sci Technol. 2020;97:366-80. https://doi.org/10.1016/j.tifs.2020.01.019.

18. Nahar L, Xiao J, Sarker SD. Introduction of phytonutrients. IXiao J., Sarker S.D. , Asakawa Y. handbook of dietary phytochemicals. Singapore: Springer; 2021. https://doi.org/10.1007/978-981-15-4148-3 2

19. Hadipour E, Taleghani A, Tayarani-Najaran N, Tayarani-Najaran Z. Biological effects of red beetroot and betalains: a review. Phytother Res. 2020;34(8): 1847-67. https://doi.org/10.1002/ptr.6653.

20. Forni C, Facchiano F, Bartoli M, Pieretti S, Facchiano A, D'Arcangelo D, et al. Beneficial role of phytochemicals on oxidative stress and age-related diseases. Biomed Res Int. 2019;2019:8748253-16. https://doi.org/10.1155/201 9/8748253.

21. Clifford T, Allerton DM, Brown MA, Harper L, Horsburgh S, Keane KM, et al. Minimal muscle damage after a marathon and no influence of beetroot juice on inflammation and recovery. Appl Physiol Nutr Metab. 2017;42(3): 263-70. https://doi.org/10.1139/apnm-2016-0525.

22. Clifford T, Bowman A, Capper T, Allerton DM, Foster E, Birch-Machin M, et al A pilot study investigating reactive oxygen species production in capillary blood after a marathon and the influence of an antioxidant-rich beetroot juice. Appl Physiol Nutr Metab. 201;10:1-4. Available from: https://www.ncbi. nlm.nih.gov/pubmed/29125915.

23. Howatson G, McHugh MP, Hill JA, Brouner J, Jewell AP, van Someren KA, et al. Influence of tart cherry juice on indices of recovery following marathon running. Scand J Med Sci Sports. 2010;20(6):843-52. https://doi. org/10.1111/j.1600-0838.2009.01005.x.

24. Lamprecht L. Antioxidants in sport nutrition. Boca Raton (FL): CRC Press/ Taylor \& Francis; 2015. Available from: https://www.ncbi.nlm.nih.gov/books/ NBK299052/

25. Nieman DC, Gillitt ND, Sha W, Meaney MP, John C, Pappan KL, et al. Metabolomics-based analysis of Banana and pear ingestion on exercise performance and recovery. J Proteome Res. 2015;14(12):5367-77. https://doi. org/10.1021/acs.jproteome.5b00909.

26. Hurst RD, Lyall KA, Roberts JM, Perthaner A, Wells RW, Cooney JM, et al. Consumption of an anthocyanin-rich extract made from New Zealand blackcurrants prior to exercise may assist recovery from oxidative stress and maintains circulating neutrophil function: a pilot study. Front Nutr. 2019;6:73. https://doi.org/10.3389/fnut.2019.00073.

27. Wootton-Beard PC, Moran A, Ryan L. Stability of the total antioxidant capacity and total polyphenol content of 23 commercially available vegetable juices before and after in vitro digestion measured by FRAP, DPPH, ABTS and Folin-Ciocalteu methods. Food Res Int. 2011;44(1):217-24. https://doi.org/10.1016/j.foodres.2010.10.033.

28. Australian Institute of Sport. The AIS sports supplement framework 2019. Available from: https://ais.gov.au/__data/assets/pdf_file/0004/698557/AISSports-Supplement-Framework-2019.

29. Lundberg JO, Weitzberg E, Gladwin MT. The nitrate-nitrite-nitric oxide pathway in physiology and therapeutics. Nat Rev Drug Discov. 2008;7(2): 156-67. https://doi.org/10.1038/nrd2466.

30. Jonvik KL, Nyakayiru J, van Loon LJ, Verdijk LB. Can elite athletes benefit from dietary nitrate supplementation. J Appl Physiol. 2015;119(6):759-61. https://doi.org/10.1152/japplphysiol.00232.2015.

31. Clifford T, Howatson G, West DJ, Stevenson EJ. Beetroot juice is more beneficial than sodium nitrate for attenuating muscle pain after strenuous eccentric-bias exercise. Appl Physiol Nutr Metab. 2017:42(11):1185-91. https://doi.org/10.1139/apnm-2017-0238.

32. MATLAB. MATLAB and statistics toolbox 2012b ed. Natick, USA: The MathWorks Inc: 2012.

33. Research E. PLS_Toolbox 8.2.1. 8.2.1 ed. Manson, USA: Eigenvector Reserch Inc.: 2016.

34. Villez K, Steppe K, De Pauw DJW. Use of unfold PCA for on-line plant stress monitoring and sensor failure detection. Biosyst Eng. 2009;103(1):23-34. https://doi.org/10.1016/j.biosystemseng.2009.01.014.

35. Mirmiran P, Houshialsadat Z, Gaeini Z, Bahadoran Z, Azizi F. Functional properties of beetroot (Beta vulgaris) in management of cardio-metabolic diseases. Nutr Metab (Lond). 2020;17:3.

36. Nieman DC, Shanely RA, Luo B, Meaney MP, Dew DA, Pappan KL. Metabolomics approach to assessing plasma 13- and 9-hydroxyoctadecadienoic acid and linoleic acid metabolite responses to $75-\mathrm{km}$ cycling. Am J Physiol Regul Integr Comp Physiol. 2014;307(1):R68-74. https://doi.org/10.1152/ajpregu.00092.2014.

37. Betteridge S, Bescos R, Martorell M, Pons A, Garnham AP, Stathis CC, et al. No effect of acute beetroot juice ingestion on oxygen consumption, glucose kinetics, or skeletal muscle metabolism during submaximal exercise in males. J Appl Physiol. 2016;120(4):391-8.

38. Lim TK. Edible medicinal and non-medicinal plants: modified stems, roots, bulbs. Heidelberg: New York Springer; 2016. https://doi.org/10.1007/ 978-3-319-26065-5.

39. Kumdam H, Murthy SN, Gummadi SN. Arabitol production by microbial fermentation - biosynthesis and future applications. Int J Sci Appl Res. 2014; 1(1):1-12.

40. Kordowska-Wiater M. Production of arabitol by yeasts: current status and future prospects. J Appl Microbiol. 2015;119(2):303-14. https://doi.org/10.1111/jam.12807.

41. Desai TA, Rao CV. Regulation of arabinose and xylose metabolism in Escherichia coli. Appl Environ Microbiol. 2010;76(5):1524-32. https://doi. org/10.1128/AEM.01970-09. 
42. Lane AN, Fan TW. Regulation of mammalian nucleotide metabolism and biosynthesis. Nucleic Acids Res. 2015;43(4):2466-85. https://doi.org/10.1093/ nar/gkv047.

43. Puigserver P. Signaling Transduction and Metabolomics. Hematology. 2018. p. 68-78.

44. Larsen N, Bussolo de Souza C, Krych L, Barbosa Cahu T, Wiese M, Kot W, et al. Potential of Pectins to Beneficially Modulate the Gut Microbiota Depends on Their Structural Properties. Front Microbiol. 2019;10:223. https:// doi.org/10.3389/fmicb.2019.00223

45. Wootton-Beard PC, Brandt K, Fell D, Warner S, Ryan L. Effects of a beetroot juice with high neobetanin content on the early-phase insulin response in healthy volunteers. J Nutr Sci. 2014;3:e9. https://doi.org/10.1017/jns.2014.7.

46. Kurotani K, Sato M, Yasuda K, Kashima K, Tanaka S, Hayashi T, et al. Evenand odd-chain saturated fatty acids in serum phospholipids are differentially associated with adipokines. PLoS ONE. 2017:12(5):e0178192. https://doi.org/1 0.1371/journal.pone.0178192.

47. Baiao DDS, Silva D, Paschoalin VMF. Beetroot, a Remarkable Vegetable: Its Nitrate and Phytochemical Contents Can be Adjusted in Novel Formulations to Benefit Health and Support Cardiovascular Disease Therapies. Antioxidants (Basel). 2020;9(10):960.

48. Brglez Mojzer E, Knez Hrncic M, Skerget M, Knez Z, Bren U. Polyphenols: Extraction Methods, Antioxidative Action, Bioavailability and Anticarcinogenic Effects. Molecules. 2016;21(7):901.

\section{Publisher's Note}

Springer Nature remains neutral with regard to jurisdictional claims in published maps and institutional affiliations.

Ready to submit your research? Choose BMC and benefit from:

- fast, convenient online submission

- thorough peer review by experienced researchers in your field

- rapid publication on acceptance

- support for research data, including large and complex data types

- gold Open Access which fosters wider collaboration and increased citations

- maximum visibility for your research: over $100 \mathrm{M}$ website views per year

At $\mathrm{BMC}$, research is always in progress.

Learn more biomedcentral.com/submissions 